\title{
Sex-Specific Association between Metabolic Abnormalities and Elevated Alanine Aminotransferase Levels in a Military Cohort: The CHIEF Study
}

\author{
Kai-Wen Chen ${ }^{1}$, Fan-Chun Meng ${ }^{2}$, Yu-Lueng Shih ${ }^{2}$, Fang-Ying Su ${ }^{3}$, Yen-Po Lin ${ }^{4}$, Felicia Lin ${ }^{1}$, \\ Jia-Wei Lin ${ }^{5}$, Wei-Kuo Chang ${ }^{2}$, Chung-Jen Lee ${ }^{6}$, Yi-Hwei Li ${ }^{3}$, Chung-Bao Hsieh ${ }^{1,2}$ and \\ Gen-Min Lin 1,2,7,* \\ 1 Department of Medicine, Hualien Armed Forces General Hospital, No. 100, Jin-Feng St., Hualien 970, \\ Taiwan; az0127@gmail.com (K.-W.C.); flwoolol@gmail.com (F.L.); albert0920@yahoo.com.tw (C.-B.H.) \\ 2 Departments of Medicine, Tri-Service General Hospital, National Defense Medical Center, Taipei 114, \\ Taiwan; drking0724@gmail.com (F.-C.M.); albreb@ms28.hinet.net (Y.-L.S.); \\ weikuohome@hotmail.com (W.-K.C.) \\ 3 Department of Public Health, Tzu-Chi University, Hualien 970, Taiwan; 104324111@gms.tcu.edu.tw (F.-Y.S.); \\ yihwei@mail.tcu.edu.tw (Y.-H.L.) \\ 4 Department of Critical Care Medicine, Yonghe Cardinal Tien Hospital, Fu-Jen Catholic University, \\ New Taipei City 234, Taiwan; b101093018@tmu.edu.tw \\ 5 Department of Dentistry, National Yang-Ming University, Taipei 112, Taiwan; ljw099533@gmail.com \\ 6 Department of Nursing, Tzu-Chi College of Technology, Hualien 970, Taiwan; guggilee@ems.tcust.edu.tw \\ 7 College of Science and Engineering, National Dong Hwa University, Hualien 974, Taiwan \\ * Correspondence: farmer507@gms.ndhu.edu.tw or farmer507@yahoo.com.tw; Tel.: +886-3-863-4086; \\ Fax: +886-3-863-4060
}

Received: 5 March 2018; Accepted: 16 March 2018; Published: 19 March 2018

\begin{abstract}
The association of metabolic syndrome (MetS) components with elevated serum alanine aminotransferase (ALT) levels, a marker of hepatic injury, may differ between men and women. However, the sex-specific association in a military young population which has a low prevalence of MetS was unclear. We conducted a cross-sectional examination in 6738 men and 766 women, aged 18-50 years, from the cardiorespiratory fitness study in armed forces (CHIEF) in eastern Taiwan. The components of MetS were defined according to the updated International Diabetes Federation (IDF) ethnic criteria for Asians. Elevated ALT levels were defined as $\geq 40 \mathrm{U} / \mathrm{L}$ for both sexes and $\geq 30 \mathrm{U} / \mathrm{L}$ for women alternatively. Multivariate logistic regression analysis was performed to determine the sex-specific association between MetS components and elevated ALT. The prevalence of MetS and elevated ALT in men were $11.9 \%$ and $12.7 \%$ respectively, and in women were $3.5 \%$, and $3.8 \%$ respectively. In men, high-density lipoprotein $<40 \mathrm{mg} / \mathrm{dL}$, blood pressures $\geq 130 / 85$ $\mathrm{mmHg}$, serum triglycerides $\geq 150 \mathrm{mg} / \mathrm{dL}$, and waist size $\geq 90 \mathrm{~cm}$ were associated with elevated ALT (odds ratios (OR) and 95\% confidence intervals: 1.59 (1.34-1.90), 1.40 (1.19-1.65), 2.00 (1.68-2.39), and $1.68(1.38-2.04)$; all $p<0.001)$; whereas in women, only fasting plasma glucose $\geq 100 \mathrm{mg} / \mathrm{dL}$ was associated with elevated ALT $\geq 40 \mathrm{U} / \mathrm{L}$ (OR: 7.59 (2.35-24.51), $p=0.001$ ) and ALT $\geq 30 \mathrm{U} / \mathrm{L}$ (2.67 $(0.89-7.95), p=0.08)$. Our findings suggest that the relationship between metabolic abnormalities and elevated ALT may differ by sex, possibly due to the MetS more prevalent in young adult men than in women.
\end{abstract}

Keywords: alanine aminotransferase; metabolic syndrome; military cohort; sex difference 


\section{Introduction}

Non-alcoholic fatty liver disease (NAFLD), characterized by excessive accumulation of hepatic fat, is defined as the presence of steatosis in more than $5 \%$ of hepatocytes [1]. NAFLD affects $17-60 \%$ of adults in different countries and the prevalence in Taiwan is estimated to be $11.5 \%$ to $57.8 \%$ [2,3]. Today, NAFLD has become a leading etiology of chronic liver disease worldwide [4]. Nonalcoholic steatohepatitis (NASH) is a more aggressive form of NAFLD and covers a wide spectrum of disease severity, including hepatitis, fibrosis, cirrhosis, and hepatocellular carcinoma [5]. NASH commonly coexists with elevated markers of liver injury, particularly serum alanine aminotransferase (ALT), which is closely related to the severity of fat accumulation in the liver and frequently used as a marker of NAFLD in relation to type 2 diabetes mellitus in several epidemiology studies [6,7].

Metabolic syndrome (MetS) is defined as central obesity occurring in parallel with two of the following components: (1) raised levels of blood pressures, triglycerides, and fasting plasma glucose; and (2) reduced high-density lipoprotein concentration based on the International Diabetes Federation (IDF) criteria [8]. In addition, obesity, diabetes mellitus, insulin resistance, dyslipidemia, and hypertension may lead to NAFLD, which has been considered as the liver's manifestation of MetS [9]. Prospective studies have also shown that elevated ALT levels related to NAFLD or NASH is associated with the occurrence of new-onset MetS and type 2 diabetes, independent of age, obesity, and alcohol intake [10,11].

Previous studies reported sex differences in the prevalence of NAFLD, with it affecting more men than women [12]. This finding was also reflected in the distribution of visceral fat, where women have less visceral fat than men [13]. Similarly, the prevalence and components of MetS may also differ by sex [14]. Studies had suggested that female hormones could protect against visceral fat accumulation and metabolic abnormalities, leading to a lower prevalence of MetS and hepatic injury related to NAFLD among premenopausal women [15]. Since there were few studies investigating the association of MetS components and elevated ALT levels between young men and women, we decided to examine the sex-specific association in a large military cohort in Taiwan.

\section{Materials and Methods}

\subsection{Study Population}

From January 2013 to December 2014, there were 9076 military participants enrolled in the cardiorespiratory fitness and hospitalization events in armed forces (CHIEF) study. We further excluded participants who had unavailable relevant covariates and those with viral hepatitis and without a ultrasound-proven fatty infiltration of liver, leaving a final sample of 7504 individuals $(82.7 \%)$ including 6738 men and 766 women, ages between 18 and 50 years for analysis. The study design has been described in detail previously [16]. In brief, each participant was asked to self-report a questionnaire including demographic information, medical history, current cigarette smoking habits, and alcohol consumption. All participants underwent physical examinations, anthropometric measurements for height, weight, and waist circumference at standing position, and hemodynamic status of pulse rate and blood pressures, which were automatically measured by the PARAMA TECH FT-201 blood pressure monitor over the right upper arm at sitting position, after taking a rest for at least $15 \mathrm{~min}$. Blood tests were performed for concentrations of fasting plasma glucose, triglycerides, total cholesterol, high-density lipoprotein, low-density lipoprotein, serum uric acid, aspartate transaminase (AST), and alanine transaminase (ALT) in the Hualien Armed Forces General Hospital which is the only military referral center in Hualien, Taiwan, able to perform the whole body health exams.

\subsection{Definitions}

In our analyses, elevated ALT levels were defined as $\geq 40 \mathrm{U} / \mathrm{L}$ for both sexes and $\geq 30 \mathrm{U} / \mathrm{L}$ for women alternatively [17]. The updated IDF definition of MetS includes the major component of waist size $\geq 90 \mathrm{~cm}$ for Asian men and $\geq 80 \mathrm{~cm}$ for Asian women in addition to two or more of the four minor 
components: (1) serum triglycerides $\geq 150 \mathrm{mg} / \mathrm{dL}$; (2) high-density lipoprotein $<40 \mathrm{mg} / \mathrm{dL}$ for men and $<50 \mathrm{mg} / \mathrm{dL}$ for women; (3) systolic blood pressure $\geq 130 \mathrm{mmHg}$, or diastolic blood pressure $\geq 85 \mathrm{mmHg}$, or use of antihypertensive medication; (4) fasting plasma glucose $\geq 100 \mathrm{mg} / \mathrm{dL}$, or use of antidiabetic medication [9]. Alternatively, the National Cholesterol Education Program Adult Treatment Panel (NCEP ATP III) guideline for MetS for men and women was defined as the presence of three or more of the previously mentioned major and minor criteria [18]. Body mass index was defined as weight $(\mathrm{kg})$ /square of height $\left(\mathrm{m}^{2}\right)$. Obese, overweight, normal-weight, and underweight were defined by a body mass index $\geq 30,25-29.9,18-24.9$, and $<18 \mathrm{~kg} / \mathrm{m}^{2}$, respectively. This study was reviewed and approved by the Institutional Review Board of the Mennonite Christian Hospital in Taiwan and written informed consent was obtained from all participants.

\subsection{Statistical Analysis}

Demographic characteristics and laboratory data are presented as means \pm standard deviations or percent for continuous and categorical variables, respectively. Chi-square or Fisher's exact tests for categorical variables and Student's $t$-tests for continuous variables were used between the two groups (normal levels of ALT vs. elevated ALT, and women vs. men). Univariate logistic regression was used to identify the risk factors for elevated ALT based on sex. Multivariate logistic regression analysis was also performed in men and women for those variables with statistically significance in the univariate analysis to determine the association between the MetS components and elevated ALT. A two-tailed value of $p<0.05$ was considered statistically significant. Analyses were performed using SAS statistical software (version 9.4, SAS Institute Inc., Cary, NC, USA).

\subsection{Ethical Approval}

All procedures performed in studies involving human participants were in accordance with the ethical standards of the institutional and/or national research committee and with the 1964 Helsinki declaration and its later amendments or comparable ethical standards (Mennonite Christian Hospital Institutional Review Board/Ethics Committee approval code: 16-05-008).

\section{Results}

\subsection{Descriptive Characteristics}

The baseline characteristics of those with and without elevated ALT $\geq 40 \mathrm{U} / \mathrm{L}$ are shown in Table 1 . The mean age of overall participants was 29 years. Participants with elevated ALT were relatively older, more likely to be male, and had more prevalent obesity, current cigarette smoking, current alcohol intake, metabolic abnormalities, and an ALT / AST ratio > 1, an indicator of hepatic injury not caused by alcohol toxicity. The prevalence of IDF- and NCEP-ATP III-defined MetS was estimated to be $11.1 \%$ and $13.6 \%$ respectively in the overall cohort and much higher in those with elevated ALT than those without. Table S1 shows similar results if elevated ALT was defined as $\geq 30 \mathrm{U} / \mathrm{L}$ for women alternatively.

Table 1. Baseline characteristics of the study cohort based on serum ALT levels.

\begin{tabular}{ccccc}
\hline & Overall & ALT $<40$ & ALT $\geq 40 \mathbf{4} / \mathbf{L}$ & \multirow{2}{*}{$\boldsymbol{p}$-Value } \\
\cline { 2 - 4 } & $\mathbf{N}=\mathbf{7 5 0 4}$ & $\mathbf{N}=\mathbf{6 6 3 2}$ & $\mathbf{N}=\mathbf{8 7 2}$ & \\
\hline Age (year) & $28.93 \pm 6.04$ & $28.69 \pm 6.06$ & $30.74 \pm 28.35$ & $<0.0001$ \\
Specialty, $\%$ & & & & $<0.0001$ \\
Air forces & 19.75 & 1.66 & 0.34 & \\
Army & 78.74 & 79.52 & 72.82 & \\
Navy & 1.51 & 18.82 & 26.83 & \\
SEX, $\%$ & 10.21 & 11.31 & & $<0.0001$ \\
Women & 89.79 & 88.69 & 98.17 & \\
Men & & & & \\
\hline
\end{tabular}


Table 1. Cont.

\begin{tabular}{|c|c|c|c|c|}
\hline & Overall & ALT $<40$ & $\mathrm{ALT} \geq 40 \mathrm{U} / \mathrm{L}$ & \multirow{2}{*}{$p$-Value } \\
\hline & $N=7504$ & $N=6632$ & $N=872$ & \\
\hline BMI $\left(\mathrm{kg} / \mathrm{m}^{2}\right), \%$ & $24.96 \pm 3.72$ & $24.52 \pm 3.48$ & $28.35 \pm 3.77$ & $<0.0001$ \\
\hline Underweight $(<18.5)$ & 2.00 & 2.22 & 0.34 & $<0.0001$ \\
\hline Normal (18.5-24.9) & 51.88 & 56.35 & 17.89 & \\
\hline Overweight (25-29.9) & 37.34 & 35.13 & 54.13 & \\
\hline Obesity $(\geq 30)$ & 8.78 & 6.30 & 27.64 & \\
\hline Current smoker, $\%$ & 33.81 & 32.78 & 41.63 & $<0.0001$ \\
\hline Current alcohol intake, $\%$ & 45.19 & 44.38 & 51.38 & $<0.0001$ \\
\hline ALT / AST ratio $\geq 1, \%$ & 47.23 & 40.65 & 97.25 & $<0.0001$ \\
\hline Elevated blood pressure, $\%$ * & 25.61 & 23.21 & 43.92 & $<0.0001$ \\
\hline Waist circumference, $\%$ & 27.60 & 23.33 & 60.09 & $<0.0001$ \\
\hline Serum TG $\geq 150 \mathrm{mg} / \mathrm{dL}, \%$ & 19.95 & 16.34 & 47.36 & $<0.0001$ \\
\hline $\mathrm{FPG} \geq 100 \mathrm{mg} / \mathrm{dL}, \%$ & 14.43 & 13.31 & 22.94 & $<0.0001$ \\
\hline Low serum HDL, \% $\$$ & 21.16 & 18.97 & 37.84 & $<0.0001$ \\
\hline Total cholesterol $\geq 200 \mathrm{mg} / \mathrm{dL}, \%$ & 20.26 & 17.84 & 38.65 & $<0.0001$ \\
\hline Metabolic syndrome (ATPIII), \% & 13.58 & 10.12 & 39.91 & 0.0001 \\
\hline Metabolic syndrome (IDF), \% & 11.06 & 7.89 & 35.21 & $<0.0001$ \\
\hline \multicolumn{5}{|c|}{$\begin{array}{l}\text { Continuous variables are expressed as mean } \pm \text { standard deviation and categorical variables as number (percentage). } \\
\text { Abbreviations: ALT, alanine aminotransferase; AST, aspartate aminotransferase; ATP III, National Cholesterol } \\
\text { Education Program Adult Treatment Panel III; BMI, body mass index; FPG, fasting plasma glucose; HDL, high } \\
\text { density lipoprotein; IDF, International Diabetes Federation; TG, triglycerides. }{ }^{*} \text { Elevated blood pressure: blood } \\
\text { pressure } \geq 130 / 85 \mathrm{~mm} \text { Hg or use of antihypertensive agents. } \int \text { Waist circumference: } \geq 90 \mathrm{~cm} \text { in men and } \geq 80 \mathrm{~cm} \text { in } \\
\text { women. }{ }^{\$} \text { Low serum HDL: }<40 \mathrm{mg} / \mathrm{dL} \text { in men and }<50 \mathrm{mg} / \mathrm{dL} \text { in women. }\end{array}$} \\
\hline
\end{tabular}

\subsection{Sex Differences}

The prevalence of elevated ALT $\geq 40 \mathrm{U} / \mathrm{L}$ in men and women stratified by age are shown in Figure 1. In general, elevated ALT levels were much more prevalent in men than women $(12.7 \% \mathrm{vs}$. $2.1 \%$ ). The prevalence of elevated ALT in men at ages of $18-23$ years was $7.0 \%$ and increased sharply to the peak of $17 \%$ at ages of 30-35 years. By contrast, the prevalence in women at ages of 18-35 years was estimated only $1.3-1.6 \%$ and rose to the peak of $5.1 \%$ at ages of $36-41$ years. Figure S1 shows that the prevalence of elevated ALT $\geq 30 \mathrm{U} / \mathrm{L}$ in women was estimated $3.8 \%$ and the peak was $9.4 \%$ at ages of $36-41$ years.

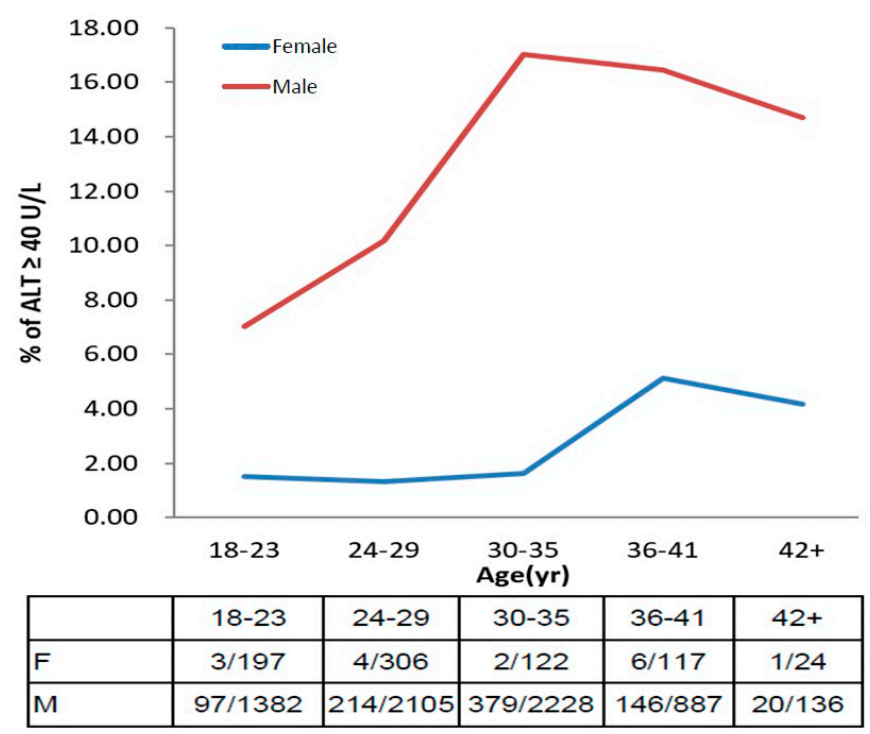

Figure 1. The age-based prevalence of elevated ALT in men and women. 
The baseline characteristics of men and women are shown in Table 2. Men were modestly older and had more prevalent obesity, current smoking, current alcohol consumption, metabolic abnormalities, elevated ALT, and ALT/AST ratio > 1 compared with women. The prevalence of IDFand NCEP-ATP III-defined MetS in men is $11.9 \%$ and $14.7 \%$ respectively, which are much higher than the $3.5 \%$ and $4.1 \%$ found in women.

Table 2. Baseline characteristics of the study cohort of men and women.

\begin{tabular}{|c|c|c|c|}
\hline \multirow{2}{*}{ Variables } & Women & Men & \multirow{2}{*}{$p$-Value } \\
\hline & $N=766$ & $N=6738$ & \\
\hline Age (year) & $28.03 \pm 6.61$ & $29.03 \pm 5.97$ & $<0.0001$ \\
\hline Specialty, \% & & & $<0.0001$ \\
\hline Air forces & 1.04 & 1.56 & \\
\hline Army & 85.51 & 77.98 & \\
\hline Navy & 13.45 & 20.47 & \\
\hline $\operatorname{BMI}\left(\mathrm{kg} / \mathrm{m}^{2}\right), \%$ & $22.59 \pm 3.11$ & $25.23 \pm 3.69$ & $<0.0001$ \\
\hline Underweight $(<18.5)$ & 6.01 & 1.54 & $<0.0001$ \\
\hline Normal (18.5-24.9) & 72.98 & 49.48 & \\
\hline Overweight (25-29.9) & 18.80 & 39.45 & \\
\hline Obesity $(\geq 30)$ & 2.22 & 9.53 & \\
\hline Current smoker, $\%$ & 10.18 & 36.49 & $<0.0001$ \\
\hline Current alcohol intake, $\%$ & 21.80 & 47.85 & $<0.0001$ \\
\hline $\mathrm{ALT}, \%$ & & & $<0.0001$ \\
\hline$<40 \mathrm{U} / \mathrm{L}$ & 97.91 & 87.30 & \\
\hline$\geq 40 \mathrm{U} / \mathrm{L}$ & 2.09 & 12.70 & \\
\hline $\mathrm{ALT} / \overline{\mathrm{AST}}$ ratio $\geq 1, \%$ & 14.75 & 50.92 & $<0.0001$ \\
\hline Elevated blood pressure, $\%$ * & 6.01 & 27.84 & $<0.0001$ \\
\hline Waist circumference, $\% \int$ & 23.37 & 28.08 & 0.0057 \\
\hline Serum TG $\geq 150 \mathrm{mg} / \mathrm{dL}, \%$ & 6.14 & 21.52 & $<0.0001$ \\
\hline $\mathrm{FPG} \geq 100 \mathrm{mg} / \mathrm{dL}, \%$ & 5.22 & 15.48 & $<0.0001$ \\
\hline Low serum HDL, \% $\$$ & 25.98 & 20.61 & 0.0006 \\
\hline Total cholesterol $\geq 200 \mathrm{mg} / \mathrm{dL}, \%$ & 14.36 & 20.93 & $<0.0001$ \\
\hline Metabolic syndrome (ATPIII), \% & 4.05 & 14.66 & $<0.0001$ \\
\hline Metabolic syndrome (IDF), \% & 3.52 & 11.92 & $<0.0001$ \\
\hline
\end{tabular}

Continuous variables are expressed as mean \pm standard deviation and categorical variables as number (percentage). Abbreviations: ALT, alanine aminotransferase; AST, aspartate aminotransferase; ATP III, National Cholesterol Education Program Adult Treatment Panel III; BMI, body mass index; FPG, fasting plasma glucose; HDL, high density lipoprotein; IDF, International Diabetes Federation; TG, triglycerides. * Elevated blood pressure: blood pressure $\geq 130 / 85 \mathrm{~mm} \mathrm{Hg}$ or use of antihypertensive agents. $\int$ Waist circumference: $\geq 90 \mathrm{~cm}$ in men and $\geq 80 \mathrm{~cm}$ in women. ${ }^{\$}$ Low serum HDL: $<40 \mathrm{mg} / \mathrm{dL}$ in men and $<50 \mathrm{mg} / \mathrm{dL}$ in women.

Table 3 shows the results of univariate analysis for men and women. In men, all variables including older age (odds ratio (OR) per five-year increase: 1.30), metabolic risk factors, and current alcohol intake (OR: 1.20) were associated with elevated ALT $\geq 40 \mathrm{U} / \mathrm{L}$. The strongest associations in the metabolic components were waist circumference $\geq 90 \mathrm{~cm}$ or obesity (OR: 4.94 and 5.27 respectively) and MetS (OR: 5.36 and 5.81 according to the NCEP-ATP III and IDF based-criteria respectively). In contrast, for women, two of the metabolic risk factors-elevated blood pressures and total cholesterol, as well as current alcohol intake-were not associated with elevated ALT. The strongest associations in the metabolic components were fasting plasma glucose $\geq 100 \mathrm{mg} / \mathrm{dL}$ (OR: 12.6) and MetS (OR: 23.5 and 20.8 based on the NCEP-ATP III and IDF based-criteria respectively). Table S2 shows consistent results for women if elevated ALT was defined as $\geq 30 \mathrm{U} / \mathrm{L}$, alternatively. The strongest associations in the metabolic components were fasting plasma glucose $\geq 100 \mathrm{mg} / \mathrm{dL}$ (OR: $5.39,95 \%$ confidence intervals (CI): 2.06-14.12), serum triglycerides $\geq 150 \mathrm{mg} / \mathrm{dL}$ (OR: 5.54, 95\% CI: 2.24-13.75), and MetS (OR: 14.63, 95\% CI: 5.98-35.75 and 14.40, 95\% CI: 5.66-36.60 based on the NCEP-ATP III and IDF based criteria, respectively). 
Table 3. Univariate analysis of risk factors predicting elevated ALT $\geq 40 \mathrm{U} / \mathrm{L}$ based on sex.

\begin{tabular}{|c|c|c|c|c|c|c|}
\hline \multirow{3}{*}{ Variables } & Overall & \multirow{3}{*}{$p$-Value } & Women & \multirow{3}{*}{$p$-Value } & Men & \multirow{3}{*}{$p$-Value } \\
\hline & $N=7504$ & & $N=766$ & & $N=6738$ & \\
\hline & OR $(95 \% \mathrm{CI})$ & & OR $(95 \% \mathrm{CI})$ & & OR $(95 \% \mathrm{CI})$ & \\
\hline \multicolumn{6}{|l|}{ BMI $\left(\mathrm{kg} / \mathrm{m}^{2}\right)$} & $<0.0001$ \\
\hline $25-29.9$ & $2.18(1.89-2.51)$ & $<0.0001$ & $2.66(0.95-7.45)$ & 0.062 & $2.01(1.74-2.32)$ & $<0.0001$ \\
\hline$\geq 30$ & $5.68(4.75-6.79)$ & $<0.0001$ & $7.00(1.46-33.6)$ & 0.015 & $5.27(4.40-6.31)$ & $<0.0001$ \\
\hline Elevated blood pressure * & $2.59(2.24-3.00)$ & $<0.0001$ & $2.29(0.51-10.4)$ & 0.28 & $2.36(2.03-2.73)$ & $<0.0001$ \\
\hline Waist circumference $\int$ & $4.95(4.27-5.73)$ & $<0.0001$ & $4.39(1.61-12.0)$ & 0.0038 & $4.94(4.26-5.74)$ & $<0.0001$ \\
\hline Serum TG $\geq 150 \mathrm{mg} / \mathrm{dL}$ & $4.61(3.97-5.34)$ & $<0.0001$ & $3.70(1.02-13.5)$ & 0.047 & $4.28(3.68-4.97)$ & $<0.0001$ \\
\hline $\mathrm{FPG} \geq 100 \mathrm{mg} / \mathrm{dL}$ & $1.94(1.63-2.30)$ & $<0.0001$ & $12.64(4.34-36.8)$ & $<0.0001$ & $1.74(1.46-2.07)$ & $<0.0001$ \\
\hline Low serum $\mathrm{HDL}^{\$}$ & $2.60(2.24-3.02)$ & $<0.0001$ & $2.93(1.08-7.91)$ & 0.034 & $2.72(2.33-3.17)$ & $<0.0001$ \\
\hline Total cholesterol $\geq 200 \mathrm{mg} / \mathrm{dL}$ & $2.90(2.50-3.37)$ & $<0.0001$ & $1.39(0.39-4.95)$ & 0.61 & $2.86(2.45-3.33)$ & $<0.0001$ \\
\hline Current alcohol intake & $1.32(1.15-1.53)$ & $<0.0001$ & $1.20(0.38-3.77)$ & 0.75 & $1.20(1.04-1.39)$ & 0.012 \\
\hline Metabolic syndrome (ATPIII) & $5.90(5.04-6.91)$ & $<0.0001$ & $23.53(8.09-68.5)$ & $<0.0001$ & $5.36(4.57-6.28)$ & $<0.0001$ \\
\hline Metabolic syndrome (IDF) & $6.35(5.38-7.49)$ & $<0.0001$ & $20.83(6.93-62.64)$ & $<0.0001$ & $5.81(4.92-6.87)$ & $<0.0001$ \\
\hline
\end{tabular}

Table 4 presents the multivariate logistic regression analyses results using age, body mass index category, total cholesterol concentrations, and the five MetS components to predict elevated ALT $\geq$ $40 \mathrm{U} / \mathrm{L}$ for the overall, male, and female groups, respectively. As expected in the overall group, men were more likely to have elevated ALT than women (OR: 3.86). In men, the strongest associations in the metabolic risk factors were being overweight and obesity (OR: 2.58 and 4.54 respectively) and serum triglycerides $\geq 150 \mathrm{mg} / \mathrm{dL}$ (OR: 2.00 ). By contrast in women, although obesity and waist circumference $\geq 80 \mathrm{~cm}$ were associated with two-fold higher risk of elevated ALT (OR: 2.24 and 2.37 respectively), the levels of statistical significance were not attained. Only fasting plasma glucose $\geq$ $100 \mathrm{mg} / \mathrm{dL}$ (OR: 7.59) was associated with elevated ALT levels $\geq 40 \mathrm{U} / \mathrm{L}$ in women. Table S3 shows that both fasting plasma glucose $\geq 100 \mathrm{mg} / \mathrm{dL}$ and serum triglycerides $\geq 150 \mathrm{mg} / \mathrm{dL}$ were borderline associated with elevated ALT levels $\geq 30 \mathrm{U} / \mathrm{L}$ in women (OR: 2.67, 95\% CI: $0.89-7.95$ and 2.77, 95\% CI: 0.95-8.12, respectively).

Table 4. Multivariate analysis of the metabolic risk factors predicting elevated ALT $\geq 40 \mathrm{U} / \mathrm{L}$ based on sex.

\begin{tabular}{|c|c|c|c|c|c|c|}
\hline \multirow{3}{*}{ Variables } & Overall & \multirow{3}{*}{$p$-Value } & Women & \multirow{3}{*}{$p$-Value } & Men & \multirow{3}{*}{$p$-Value } \\
\hline & $\mathrm{N}=7504$ & & \multirow{2}{*}{$\begin{array}{c}\mathrm{N}=766 \\
\text { OR }(95 \% \mathrm{CI})\end{array}$} & & $N=6738$ & \\
\hline & OR $(95 \%$ CI $)$ & & & & OR $(95 \%$ CI $)$ & \\
\hline Age (by five-year increment) & $1.03(0.96-1.10)$ & 0.46 & $1.16(0.79-1.72)$ & 0.46 & $1.02(0.95-1.10)$ & 0.53 \\
\hline \multicolumn{7}{|l|}{ BMI $\left(\mathrm{kg} / \mathrm{m}^{2}\right)$} \\
\hline $25-29.9$ & $2.53(2.03-3.15)$ & $<0.0001$ & $1.24(0.30-5.17)$ & 0.77 & $2.58(2.06-3.22)$ & $<0.0001$ \\
\hline $\mathrm{FPG} \geq 100 \mathrm{mg} / \mathrm{dL}$ & $1.10(0.90-1.33)$ & 0.35 & $7.59(2.35-24.51)$ & 0.001 & $1.05(0.86-1.28)$ & 0.62 \\
\hline Elevated blood pressure * & $1.40(1.19-1.64)$ & $<0.0001$ & $1.15(0.20-6.74)$ & 0.87 & $1.40(1.19-1.65)$ & $<0.0001$ \\
\hline Waist circumference $\int$ & $1.69(1.39-2.05)$ & $<0.0001$ & $2.37(0.62-9.15)$ & 0.21 & $1.68(1.38-2.04)$ & $<0.0001$ \\
\hline Low serum HDL ${ }^{\$}$ & $1.61(1.35-1.92)$ & $<0.0001$ & $1.71(0.52-5.60)$ & 0.37 & $1.59(1.34-1.90)$ & $<0.0001$ \\
\hline Total cholesterol $\geq 200 \mathrm{mg} / \mathrm{dL}$ & $1.81(1.53-2.16)$ & $<0.0001$ & $0.95(0.21-4.20)$ & 0.94 & $1.84(1.55-2.19)$ & $<0.0001$ \\
\hline
\end{tabular}

Data are expressed as odds ratio (OR) and $95 \%$ confidence intervals (CI). Abbreviations: BMI, body mass index; FPG, fasting plasma glucose; HDL, high density lipoprotein; N/A, not available; TG, triglycerides. * Elevated blood pressure: blood pressure $\geq 130 / 85 \mathrm{~mm} \mathrm{Hg}$ or use of antihypertensive agents. $\int$ Waist circumference: $\geq 90 \mathrm{~cm}$ in men and $\geq 80 \mathrm{~cm}$ in women. ${ }^{\$}$ Low serum HDL: $<40 \mathrm{mg} / \mathrm{dL}$ in men and $<50 \mathrm{mg} / \mathrm{dL}$ in women. 


\section{Discussion}

This is the first cross-sectional cohort study focusing on the prevalence of MetS and the metabolic risk factors for abnormal levels of liver enzyme in young military men and women in Taiwan. We found a low prevalence of MetS in men and women which is consistent with that in other young Asian adults (14-15.6\% in men and $2.3-5.4 \%$ in women) $[19,20]$. Furthermore, we identified that the association between MetS components and elevated ALT levels might differ by sex in young adults.

Metabolic abnormalities associated with hepatic injury and elevated ALT levels have been reported in previous studies for other Asian populations [19-21]. In the present study, an ALT/AST ratio $>1$ was found in more than $97 \%$ of those with elevated ALT, presumably from NAFLD [22]. We also noticed that young adults appeared to be at risk of having elevated ALT levels, especially in the age 30-40 group. Schmucker [23] reported that these age-related liver function changes can be explained by change with age in liver volume, hepatic dense body compartment, shifts in the expression of a variety of proteins, a lower inflammatory response to oxidative stress, diminished hepatobiliary functions, and increased fibrosis. In addition, Dong et al. [24] demonstrated that ALT levels decreased with age, independent of sex, alcohol use, and metabolic risk factors in a longitudinal follow-up.

The association of the MetS components with elevated ALT may differ by sex. Previous studies have shown that prevalence of NAFLD in non-diabetic men was higher than that in non-diabetic women in an Asian population [25], and this was consistent with the finding in another study of a U.S. adult cohort [26]. These data suggested that diabetes or high fasting plasma glucose in women is highly correlated with NAFLD and inflammation status on liver. Liver-fat accumulation or NAFLD was also reported with an association with insulin resistance in women $[27,28]$. Moreover, Levitzky et al. uncovered that impaired fasting glucose levels in women were associated with higher risk of coronary heart disease risk, which may share a similar pathogenesis with NAFLD [29], whereas this was not shown in men. By contrast, the association of obesity dyslipidemia, and hypertension rather than abnormal fasting plasma glucose with elevated ALT seemed to be stronger in men. The mechanism for the difference in association based on sex is not clear and needs further investigation.

Due to our female population being mostly at premenopausal ages, the prevalence of MetS and elevated ALT were particularly low. This result was also shown in other epidemiology studies $[19,30]$. Hamaguchi et al. have revealed an association of the postmenopausal state with NAFLD and indicated that the postmenopausal state was a risk factor for NAFLD [31]. Estrogen can provide many benefits in body metabolism such as maintaining proper fluid balance, increasing high density lipoproteins and decreasing low density lipoproteins. Female estrogens also have many benefits for the liver such as inhibition of fibrogenesis, promotion of antioxidant effects, increase in innate immunity, inhibition of cellular senescence, and protection of mitochondrial structure and function [32]. Loss of estrogen has been associated with an increase of central fat [33]. In addition, Grobe et al. found women without NAFLD had higher levels of serum estradiol compared with NAFLD patients [15]. Therefore female hormones, especially estrogen, may have a protective effect of against NAFLD in women.

This study has several limitations. First, behavioral characteristics such as smoking, drinking, and physical activity are collected by self-report and lack of quantitative measures, which may result in some errors and confounding effects. Second, the temporal association between the five MetS components and elevated ALT levels could not be made as a cross-sectional design in nature. Third, there were only 766 women compared to 6738 men in the present study. With this relatively limited sample size of the female subjects, it is important to note that the conclusions drawn from women were statistically less powerful and evident, and deserve further study to verify our findings.

\section{Conclusions}

The relationship between metabolic abnormalities with elevated ALT levels may differ by sex in young military adults below 50 years of age in Taiwan. Fasting plasma glucose $\geq 100 \mathrm{mg} / \mathrm{dL}$ was more specific to elevated ALT in women, whereas obesity, dyslipidemia, and hypertension were more 
specific to elevated ALT in men. The mechanisms for the sex difference might be related to the MetS and current alcoholic intake more prevalent in young adult men than in women.

Supplementary Materials: The following are available online at http:/ /www.mdpi.com/1660-4601/15/3/545/s1, Table S1: Baseline Characteristics of the Study Cohort based on Serum ALT levels, Table S2: Univariate Analysis of Risk Factors Predicting Elevated ALT $\geq 30$ U/L in Women, Table S3: Multivariate Analysis of the Risk Factors Predicting Elevated ALT $\geq 30$ U/L based on Sex, Figure S1: The age-based prevalence of elevated ALT in men and women. "Elevated ALTs are defined as ALT level $\geq 40 \mathrm{U} / \mathrm{L}$ in men and $\geq 30 \mathrm{U} / \mathrm{L}$ in women.

Acknowledgments: This study was funded by the Hualien Armed Forces General Hospital (grant number 805-C105-10 and 805-C107-5) and the Ministry of National Defense Medical Affairs Bureau (grant number MAB-106-124).

Author Contributions: Kai-Wen Chen wrote the paper; Fan-Chun Meng, Yu-Lueng Shih, Yen-Po Lin, Wei-Kuo Chang, Chung-Jen Lee, and Chung-Bao Hsieh made critical suggestions and revisions on the study; Felicia Lin and Jia-Wei Lin collected the data; Fang-Ying Su and Yi-Hwei Li analyzed the data; Gen-Min Lin conceived, designed, and corresponded to the study.

Conflicts of Interest: The authors declare no conflict of interest.

\section{References}

1. European Association for the Study of the Liver (EASL); European Association for the Study of Diabetes (EASD); European Association for the Study of Obesity (EASO). EASL-EASD-EASO Clinical Practice Guidelines for the management of non-alcoholic fatty liver disease. J. Hepatol. 2016, 64, 1388-1402.

2. Chen, C.-H.; Huang, M.-H.; Yang, J.-C.; Nien, C.-K.; Yang, C.-C.; Yeh, Y.-H.; Yueh, S.-K. Prevalence and Risk Factors of Nonalcoholic Fatty Liver Disease in an Adult Population of Taiwan: Metabolic Significance of Nonalcoholic Fatty Liver Disease in Nonobese Adults. J. Clin. Gastroenterol. 2006, 40, 745-752. [CrossRef] [PubMed]

3. Hsiao, P.J.; Kuo, K.K.; Shin, S.J.; Yang, Y.H.; Lin, W.Y.; Yang, J.F.; Chiu, C.C.; Chuang, W.L.; Tsai, T.R.; $\mathrm{Yu}$, M.L. Significant correlations between severe fatty liver and risk factors for metabolic syndrome. J. Gastroenterol. Hepatol. 2007, 22, 2118-2123. [CrossRef] [PubMed]

4. Vernon, G.; Baranova, A.; Younossi, Z.M. Systematic review: The epidemiology and natural history of non-alcoholic fatty liver disease and non-alcoholic steatohepatitis in adults. Aliment. Pharmacol. Ther. 2011, 34, 274-285. [CrossRef] [PubMed]

5. Starley, B.Q.; Calcagno, C.J.; Harrison, S.A. Nonalcoholic fatty liver disease and hepatocellular carcinoma: A weighty connection. Hepatology 2010, 51, 1820-1832. [CrossRef] [PubMed]

6. Xu, L.; Jiang, C.Q.; Schooling, C.M.; Zhang, W.S.; Cheng, K.K.; Lam, T.H. Liver enzymes and incident diabetes in China: A prospective analysis of 10764 participants in the Guangzhou Biobank Cohort Study. J. Epidemiol. Community Health 2015, 69, 1040-1044. [CrossRef] [PubMed]

7. Sattar, N.; Scherbakova, O.; Ford, I.; O’Reilly, D.S.J.; Stanley, A.; Forrest, E.; MacFarlane, P.W.; Packard, C.J.; Cobbe, S.M.; Shepherd, J. Elevated Alanine Aminotransferase Predicts New-Onset Type 2 Diabetes Independently of Classical Risk Factors, Metabolic Syndrome, and C-Reactive Protein in the West of Scotland Coronary Prevention Study. Diabetes 2004, 53, 2855-2860. [CrossRef] [PubMed]

8. Alberti, K.G.M.M.; Zimmet, P.; Shaw, J. Metabolic syndrome-A new world-wide definition. A Consensus Statement from the International Diabetes Federation. Diabet. Med. 2006, 23, 469-480. [CrossRef] [PubMed]

9. Burgert, T.S.; Taksali, S.E.; Dziura, J.; Goodman, T.R.; Yeckel, C.W.; Papademetris, X.; Constable, R.T.; Weiss, R.; Tamborlane, W.V.; Savoye, M.; et al. Alanine Aminotransferase Levels and Fatty Liver in Childhood Obesity: Associations with Insulin Resistance, Adiponectin, and Visceral Fat. J. Clin. Endocrinol. Metab. 2006, 91, 4287-4294. [CrossRef] [PubMed]

10. Fan, J.G.; Li, F.; Cai, X.B.; Peng, Y.D.; Ao, Q.H.; Gao, Y. Effects of nonalcoholic fatty liver disease on the development of metabolic disorders. J. Gastroenterol. Hepatol. 2007, 22, 1086-1091. [CrossRef] [PubMed]

11. Doi, Y.; Kubo, M.; Yonemoto, K.; Ninomiya, T.; Iwase, M.; Tanizaki, Y.; Shikata, K.; Iida, M.; Kiyohara, Y. Liver Enzymes as a Predictor for Incident Diabetes in a Japanese Population: The Hisayama Study. Obesity 2007, 15, 1841-1850. [CrossRef] [PubMed]

12. Carulli, L.; Lonardo, A.; Lombardini, S.; Marchesini, G.; Loria, P. Gender, fatty liver and GGT. Hepatology 2006, 44, 278-279. [CrossRef] [PubMed] 
13. Lemieux, S.; Prud'homme, D.; Bouchard, C.; Tremblay, A.; Despres, J.P. Sex differences in the relation of visceral adipose tissue accumulation to total body fatness. Am. J. Clin. Nutr. 1993, 58, 463-467. [CrossRef] [PubMed]

14. Lee, S.; Ko, Y.; Kwak, C.; Yim, E.-S. Gender differences in metabolic syndrome components among the Korean 66-year-old population with metabolic syndrome. BMC Geriatr. 2016, 16, 27.

15. Gutierrez-Grobe, Y.; Ponciano-Rodriguez, G.; Ramos, M.H.; Uribe, M.; Mendez-Sanchez, N. Prevalence of nonalcoholic fatty liver disease in premenopausal, posmenopausal and polycystic ovary syndrome women. The role of estrogens. Ann. Hepatol. 2010, 9, 402-409. [PubMed]

16. Lin, G.M.; Li, Y.H.; Lee, C.J.; Shiang, J.C.; Lin, K.H.; Chen, K.W.; Chen, Y.J.; Wu, C.F.; Lin, B.S.; Yu, Y.S.; et al. Rationale and design of the cardiorespiratory fitness and hospitalization events in armed forces study in Eastern Taiwan. World J. Cardiol. 2016, 8, 464-471. [CrossRef] [PubMed]

17. Ruhl, C.E.; Everhart, J.E. Determinants of the association of overweight with elevated serum alanine aminotransferase activity in the United States. Gastroenterology 2003, 124, 71-79. [CrossRef] [PubMed]

18. Huang, P.L. A comprehensive definition for metabolic syndrome. Dis. Models Mechan. 2009, 2, $231-237$. [CrossRef] [PubMed]

19. Tsai, T.Y.; Cheng, J.F.; Lai, Y.M. Prevalence of metabolic syndrome and related factors in Taiwanese high-tech industry workers. Clinics 2011, 66, 1531-1535. [CrossRef] [PubMed]

20. Perera, S.; Lohsoonthorn, V.; Jiamjarasrangsi, W.; Lertmaharit, S.; Williams, M.A. Association Between Elevated Liver Enzymes and Metabolic Syndrome among Thai Adults. Diabetes Metab. Syndr. 2008, 2, 171-178. [CrossRef] [PubMed]

21. Kim, H.C.; Choi, K.S.; Jang, Y.H.; Shin, H.W.; Kim, D.J. Normal serum aminotransferase levels and the metabolic syndrome: Korean National Health and Nutrition Examination Surveys. Yonsei Med. J. 2006, 47, 542-550. [CrossRef] [PubMed]

22. Sorbi, D.; Boynton, J.; Lindor, K.D. The ratio of aspartate aminotransferase to alanine aminotransferase: Potential value in differentiating nonalcoholic steatohepatitis from alcoholic liver disease. Am. J. Gastroenterol. 1999, 94, 1018-1022. [CrossRef] [PubMed]

23. Schmucker, D.L. Age-related changes in liver structure and function: Implications for disease? Exp. Gerontol. 2005, 40, 650-659. [CrossRef] [PubMed]

24. Dong, M.H.; Bettencourt, R.; Brenner, D.A.; Barrett-Connor, E.; Loomba, R. Serum Levels of Alanine Aminotransferase Decrease with Age in Longitudinal Analysis. Clin. Gastroenterol. Hepatol. 2012, 10. [CrossRef] [PubMed]

25. Chen, S.C.-C.; Tsai, S.P.; Jhao, J.-Y.; Jiang, W.-K.; Tsao, C.K.; Chang, L.-Y. Liver Fat, Hepatic Enzymes, Alkaline Phosphatase and the Risk of Incident Type 2 Diabetes: A Prospective Study of 132,377 Adults. Sci. Rep. 2017, 7, 4649. [CrossRef] [PubMed]

26. Lazo, M.; Hernaez, R.; Eberhardt, M.S.; Bonekamp, S.; Kamel, I.; Guallar, E.; Koteish, A.; Brancati, F.L.; Clark, J.M. Prevalence of Nonalcoholic Fatty Liver Disease in the United States: The Third National Health and Nutrition Examination Survey, 1988-1994. Am. J. Epidemiol. 2013, 178, 38-45. [CrossRef] [PubMed]

27. Tiikkainen, M.; Tamminen, M.; Häkkinen, A.-M.; Bergholm, R.; Vehkavaara, S.; Halavaara, J.; Teramo, K.; Rissanen, A.; Yki-Järvinen, H. Liver-Fat Accumulation and Insulin Resistance in Obese Women with Previous Gestational Diabetes. Obesity Res. 2002, 10, 859-867. [CrossRef] [PubMed]

28. Foghsgaard, S.; Andreasen, C.; Vedtofte, L.; Andersen, E.S.; Bahne, E.; Strandberg, C.; Buhl, T.; Holst, J.J.; Svare, J.A.; Clausen, T.D.; et al. Nonalcoholic Fatty Liver Disease Is Prevalent in Women With Prior Gestational Diabetes Mellitus and Independently Associated With Insulin Resistance and Waist Circumference. Diabetes Care 2017, 40, 109-116. [CrossRef] [PubMed]

29. Levitzky, Y.S.; Pencina, M.J.; D’Agostino, R.B.; Meigs, J.B.; Murabito, J.M.; Vasan, R.S.; Fox, C.S. Impact of Impaired Fasting Glucose on Cardiovascular Disease. J. Am. Coll. Cardiol. 2008, 51, 264-270. [CrossRef] [PubMed]

30. Hwang, L.C.; Bai, C.H.; Chen, C.J. Prevalence of Obesity and Metabolic Syndrome in Taiwan. J. Formos. Med. Assoc. 2006, 105, 626-635. [CrossRef]

31. Hamaguchi, M.; Kojima, T.; Ohbora, A.; Takeda, N.; Fukui, M.; Kato, T. Aging is a risk factor of nonalcoholic fatty liver disease in premenopausal women. World J. Gastroenterol. 2012, 18, 237-243. [CrossRef] [PubMed] 
32. Brady, C.W. Liver disease in menopause. World J. Gastroenterol. 2015, 21, 7613-7620. [CrossRef] [PubMed]

33. Völzke, H.; Schwarz, S.; Baumeister, S.E.; Wallaschofski, H.; Schwahn, C.; Jörgen Grabe, H.; Kohlmann, T.; John, U.; Dören, M. Menopausal status and hepatic steatosis in a general female population. Gut 2007, 56, 594-595. [CrossRef] [PubMed] 